\title{
Experimental and modeling studies of density and viscosity behavior of a live fluid due to $\mathrm{CO}_{2}$ injection at reservoir condition
}

\author{
David C. Santos ${ }^{1,2}$, Marina N. Lamim ${ }^{1}$, Daniela S. Costa ${ }^{2}$, Ana Mehl ${ }^{1}$, Paulo Couto ${ }^{2,3}$, and Márcio L. L. Paredes ${ }^{4, *}$ \\ ${ }^{1}$ School of Chemistry, Federal University of Rio de Janeiro, RJ 21945-970, Brazil \\ ${ }^{2}$ Laboratory of Enhanced Oil Recovery, Federal University of Rio de Janeiro, RJ 21941-594, Brazil \\ ${ }^{3}$ Civil Engineering Program, COPPE, Federal University of Rio de Janeiro, RJ 21945-970, Brazil \\ ${ }^{4}$ Institute of Chemistry, Rio de Janeiro State University, RJ 20550-900, Brazil
}

Received: 10 February 2021 / Accepted: 28 April 2021

\begin{abstract}
In this study, highly accurate measurements of density and dynamic viscosities of a recombined live oil and its mixture with additional $\mathrm{CO}_{2}$ were performed. The experiments were carried out under pressure and temperature gradients found in Brazilian Pre-salt reservoirs, that is, in the pressure range from (27.6 to 68.9) $\mathrm{MPa}$ and at (333.15 and 353.15) K. The assumption of volume change on mixing is evaluated from the experimental results, and the influence of pressure and temperature on the volume change upon mixing is assessed. The densities of mixtures are calculated considering ( $i$ ) the excess volume approach, and ( $i i)$ no volume change. The densities are better correlated using the excess volume approach with Average Absolute Deviations (AAD) of $0.03 \%$. Thirteen mixing rules of viscosity are examined by comparing the predicted values with the experimental viscosity of the recombined live oil $+\mathrm{CO}_{2}$ mixture. The performance of some rules using compositional fractions (molar, volume and weight) is also evaluated. Thus, a total of 28 different ways to calculate the mixture viscosities were tested in this study. The worst result was obtained with Bingham's method, leading to $148.6 \%$ AAD. The best result was obtained from Lederer's method with $2 \%$ AAD and a maximum deviation of $5.8 \%$ using volume fractions and the fitting parameter $\alpha$. In addition, deviations presented by the predictive methods of Chevron, Double log, and Kendall did not exceed 9\% AAD, using weight fractions (Chevron and Double log) and molar fractions (Kendall and Monroe).
\end{abstract}

\section{Nomenclature}

$\mathrm{AAD}$

EOR

K

$K_{v}$

$L$

$M$

$\mathrm{MD}$

$P$

$Q$

$r$

$R$

RLO

T

u

$\mathrm{U}_{c}$

VBI
Average Absolute Deviations

Enhanced Oil Recovery

Fitting parameters

Calibration factor of viscosimeter

Length of the capillary tube, $\mathrm{cm}$

Mixing rule

Maximum Deviation

Pressure, MPa

Volumetric flow rate, $\mathrm{cm}^{3} \mathrm{~s}^{-1}$

Tube radius, $\mathrm{cm}$

Residual viscosity

Recombined Live Oil

Temperature, K

Standard uncertainty

Expanded standard uncertainty

Viscosity Blending Index
$w$
Weight fraction
$x \quad$ Compositional fraction

\section{Greek Letters}

$\begin{array}{ll}\beta_{i j} & \text { Binary coefficient } \\ \rho & \text { Density, } \mathrm{kg} \mathrm{m}^{-3} \\ \sigma & \text { Standard Deviation } \\ \tau & \text { Oscillation period, } \mu \mathrm{s} \\ \mu & \text { Dynamic viscosity, cP }\end{array}$

\section{Subscripts and Superscripts}

$\begin{array}{ll}\text { excess } & \text { Excess volume } \\ \text { exp } & \text { Experimental property } \\ \text { calc } & \text { Calculated property } \\ \text { ideal,mix } & \text { Ideal property of mixture } \\ w & \text { Composition in weight } \\ m & \text { Composition in mole } \\ v & \text { Composition in volume }\end{array}$

\footnotetext{
* Corresponding author: paredes@uerj.br
} 


\section{Introduction}

Enhanced Oil Recovery (EOR) processes demonstrate great potential in recovering trapped oil at the pore scale providing opportunities to recover oils that would not be produced. The design and development of these processes require detailed knowledge of thermodynamic and transport properties of reservoir fluids. For instance, for reservoir simulation, it is essential to predict the viscosity of each phase as a function of temperature and pressure to model the fluid flow [1-7]. Oil recovery is predominantly influenced by the capillary number, which characterizes the ratio of viscous forces to surface or interfacial tension forces $[8,9]$.

Carbon dioxide $\left(\mathrm{CO}_{2}\right)$ miscible flooding is among the most effective nonthermal EOR methods. In that method, $\mathrm{CO}_{2}$ is injected through injection wells into the reservoir under high pressure causing a reduction in oil viscosity and swelling of the oil [10-12]. Both oil swelling and viscosity reduction can improve crude oil mobility. For these reasons, there is a growing interest in using $\mathrm{CO}_{2}$-based methods for EOR purposes in Brazilian Pre-salt reservoirs, where oils with a high content of dissolved $\mathrm{CO}_{2}$ are found, reaching more than $40 \mathrm{~mol} \%[13,14]$.

As the injection of $\mathrm{CO}_{2}$ causes changes in crude and gas thermophysical properties and phase equilibria [15-19], it is necessary to recalculate the equilibrium of the $\mathrm{CO}_{2}$-oil system for the $\mathrm{CO}_{2}$ injection scenario as well as assessing the viscosity-pressure behavior. Thus, it is required additional experimental data of density and viscosity as a function of temperature and pressure of the mixture comprising oil with dissolved $\mathrm{CO}_{2}$. However, there is usually only a limited set of experimental data in PressureVolume-Temperature (PVT) reports of live oils. Consequently, the viscosity and density over a broad range of temperature and pressure must be predicted using correlations or predictive mixing rules.

Previous studies have demonstrated that viscosity behaves differently from other additive properties, such as molar mass, density, or solubility parameter [20, 21]. However, there are also other mixing rules in literature, most of which were proposed to estimate the viscosity of the liquid mixtures using the viscosity of the components at a given pressure and temperature. The most known mixing rule was proposed by Arrhenius [22] who proposed an expression to calculate the viscosity of liquid mixtures base on volume fractions. Also, it has been the basis for several subsequent studies. For instance, Bingham [23] published a rule based on the ideal solution for the reciprocal of viscosity, and Kendall and Monroe [24] proposed a power-law equation with mole fraction which was in good agreement with experimental viscosities of liquid systems with ideal-like behavior.

For petroleum blends, more-complex mixing rules have already been proposed. For instance, Lederer [25] proposed a modified Arrhenius equation by introducing an adjustable factor, $\alpha$. Shu [26] extended the Lederer method with a general formula for $\alpha$ as a function of the density and viscosity of the binary pairs. Cragoe [27] presented a method involving the use of correction factors. Moreover, Chirinos [28] and Double-log method [29] introduced the use of double logarithms and constants for predicting the kinematic viscosity of bitumens and heavy oils mixed with diluents, and Miadonye et al. [28] developed a mixing rule for petroleum mixtures including two parameters that account for viscosity interaction and viscosity reduction. Other methods, such as the Refutas index method [30], and the Chevron equation [31] are based on the Viscosity Blending Index (VBI). The VBI of the mixture is the weight- and volume-weighted, respectively, sum of the VBI of the components, which in turn are calculated from the kinematic viscosity.

Although the mixing rules were originally designed to be used preferably on certain ranges, which are specified by some physical or chemical properties of the liquids, empirical observations have already proven that they are useful in a great variety of applications such as heavy oil and bitumen flow [32], solvent-based bitumen recovery processes [33], and crude oil blends formulation [34]. In this context, several studies have used or evaluated the performance of the above-mentioned mixing rules, as well as other correlations [3, 21, 32, 34-42].

Despite many studies, it is not possible to state that there is a method that presents a reasonable performance for all types of systems. Hence, it is still a challenge to find a proper mixing rule for a specific system. For instance, Centeno et al. [32] evaluated 17 mixing rules for predicting kinematic viscosity of oils and their blends at several proportions. Only four rules presented acceptable accuracy (Chevron, Walther, Einstein, and Power law), nevertheless, no rule was capable of estimating viscosity for all the crude oils. Zhang et al. [21] tested five rules (Chirinos, Arrhenius, Cragoe, Shu, and Power Law) to predict the viscosity blending behavior of extracted fractions of a Canadian bitumen. The Power Law method (which requires the calculation of a parameter by regression analysis) presented the best result with $0.6 \%$ AAD. Moreover, Hernández et al. [34] reported that only mixing rules with multiple fitting parameters have low errors in predicting the kinematic viscosity of crude oil blends over a wide viscosity range $(1000-8000 \mathrm{cSt})$. The correlative method proposed by Ratcliff and Khan [43], which involves four fitting parameters, showed the best performance with a relative standard error of $16.2 \%$. Forty seven different mixtures of crude oil were tested. Recently, Sánchez and Klerk [42] determined which mixing rules could be applied for binary mixtures of $1-10 \%$ by weight of solvents and bitumen. It was found that the mixing rule of Chirinos [28], and that by Miadonye et al. [28] gave the better viscosity estimation with an absolute average relative deviation of around $30 \%$.

There are only a few attempts in the literature to evaluate the performance of the mixing rules of viscosity at moderate to high pressure. For instance, Nourozieh et al. [29] evaluated the effect of solvent weight fraction on the viscosity and density of binary mixtures of bitumen and n-heptane at pressures up to $10 \mathrm{MPa}$ and temperatures from (295 to 463) K. In their study, seven different mixing rules of viscosity (Arrhenius, Power Law, Cragoe, Lederer, Shu, Lobe, and Double-log) were tested. The viscosity data were well represented by the Power law and Cragoe's models with $7.0 \%$ and $13.6 \%$ AAD, respectively. 
There are also methods in the literature specifically proposed for mixtures with $\mathrm{CO}_{2}$. Mehrotra [35] presented two mixing rules involving fitting parameters for the viscosity of five different $\mathrm{CO}_{2}$-saturated bitumen fractions at pressures up to $10 \mathrm{MPa}$. The deviations from the experimental data reached up to $68 \%$ depending on the bitumen fraction. Lian et al. [44] proposed a modified viscosity model based on the Peng-Robinson equation of state [45], which also involved fitting parameters, for the $\mathrm{CO}_{2}$-oil system under high pressures and high temperatures. The modified viscosity model provided a relative error of around $5 \%$. Moreover, Nazeri et al. [46] presented new predictive models based on the corresponding states for predicting viscosity of the $\mathrm{CO}_{2}$-rich multicomponent mixtures. Although the proposed models presented low deviations, typically $<5 \%$, they require as input data critical properties, acentric factor and molar mass, among others. As crude oils are mixtures of unknown effective composition, obtaining these properties is not convenient because they are not measured directly for oils and need additional correlations to be obtained, which, in turn, are subject to high levels of inaccuracy. Although there are some limitations, these studies are particularly interesting, as they have the possibility of being used to predict the viscosity of liquids that form from complex fluid-fluid interactions resulting from the injection of $\mathrm{CO}_{2}$ into oil reservoirs [47].

Nasrabadi et al. [48] point out that for successful $\mathrm{CO}_{2}$ injection projects there is a need to have accurate density data for $\mathrm{CO}_{2}$ /oil mixture at different $\mathrm{CO}_{2}$ compositions. Therefore, it is necessary to deeply understand the effect of $\mathrm{CO}_{2}$ solubility on oil density. Elias and Trevisan [49] have studied the solubility and displacement behavior of viscous crude with $\mathrm{CO}_{2}$ and have found that the oil exhibits an increase in density due to $\mathrm{CO}_{2}$ solubility increase. Ashcroft and Ben Isa [50] showed that the dilution of hydrocarbons with gases other than $\mathrm{CO}_{2}$ results in a decrease in density, while the addition of $\mathrm{CO}_{2}$ increases the density. Nasir and Nurul [51] reported that simulation results of miscible displacement are sensitive to the oil and injected gas properties. For instance, it was reported that uncertainty in oil viscosity and density could give errors in the oil recovery predictions by at least $20 \%$ and $14 \%$, respectively. The uncertainties in the injected gas properties would generate more significant errors reaching up to $60 \%$ and $18 \%$, respectively. Furthermore, Lansangan and Smith [52] pointed out that the viscosities of $\mathrm{CO}_{2}$ / crude oil mixtures decrease monotonically, while the density increases with increasing the $\mathrm{CO}_{2}$ concentration.

In an attempt to understand the volumetric behavior of $\mathrm{CO}_{2}$-rich fluids in oil reservoirs, both academia and industry have been also using $\mathrm{CO}_{2}+$ hydrocarbon mixtures as a model system. To better simulate the crude oil PVT behavior, it is necessary to consider at least two different kinds of alkanes. However, the amount of density data available in the literature for more complex rather than binary systems is very scarce. In fact, to the best of our knowledge, only two studies covering the temperature and pressure conditions typically found in offshore reservoirs are available in the literature for ternary mixtures comprising dissolved $\mathrm{CO}_{2}[53,54]$. In these studies, the temperature, pressure, and $\mathrm{CO}_{2}$ mole fraction ranged from (273.15 to 363.15$) \mathrm{K}$, (5 and 100 ) MPa, and between 0.2 and 0.95 , respectively.

In this study, the effects of temperature, pressure and $\mathrm{CO}_{2}$ addition on the density and viscosity of a Recombined Live Oil (RLO) are evaluated. Different schemes for predicting these properties were tested. Thus, the volume change upon mixing for the mixture is evaluated from the experimental density. Furthermore, the performances of 13 mixing rules for viscosity, available in the literature, are tested by comparing the predicted values with the experimental dynamic viscosities of the $\mathrm{RLO}+\mathrm{CO}_{2}$ mixtures. The experiments were carried out in a PVT cell at temperatures and a pressure range representative of temperatures and gravitational pressure gradients found in some Brazilian reservoirs, i.e., at temperatures of (333.15 and 353.15) K and pressure up to 68.9 MPa.

\section{Materials and methods}

\subsection{Materials}

A dead oil from a Brazilian oil field was used in the present study. The composition determined through Gas Chromatography (GC) provided the carbon number distribution (up to $\mathrm{C}_{29}$ ) in terms of weight fractions. Katz and Firoozabadi [55] average molecular masses were used to convert weight to mole fraction. The molecular mass was calculated by the sum of the molecular mass of the constituents weighted by their respective mole fractions. The molecular weight of the dead oil was measured by freezing point depression and the measured value was $290 \mathrm{~g} \mathrm{~mol}^{-1}$.

The gases along with their suppliers and purities are presented in Table 1. All reagents were used without further purification. The dead oil composition and the molecular masses can be found in Table 2 .

For the preparation of the RLO (dead oil $+\mathrm{CH}_{4}+\mathrm{CO}_{2}$ ), the dead oil was first transferred gravimetrically to a high-pressure cylinder (sample cylinder) by using a Sartorius balance (Cubis MSU 10202S) with expanded standard uncertainty, $U_{c}$, of $0.06 \mathrm{~g}$. The cylinder was divided into two parts by means of an inner piston. One side was filled with water, which was used as a hydraulic fluid, whereas the other side was filled with the dead oil. The cylinder was closed, and the sample side was bled in order to remove trapped air. Thus, a volumetric pump (Quizix Q6000) was used to inject the $\mathrm{CO}_{2}$ and methane, separately, (by sample side) within the measurement cell. The return line of the hydraulic fluid that connects the sample cylinder to an external vessel was used to control the pressure in the system. Consequently, the masses of injected $\mathrm{CO}_{2}$ and methane into the measuring cell were directly determined by weighing the cylinder.

After the gas injections into the dead oil, the mixture was pressurized at $40 \mathrm{MPa}$ and the temperature was maintained at $333.15 \mathrm{~K}$. The cylinder was agitated using an automatic rocker for $24 \mathrm{~h}$ to generate the movement of a Hastelloy ball placed inside the cylinder to achieve the homogenization of the prepared mixture. The estimated 
Table 1. Specifications of chemicals used in this study. ${ }^{\mathrm{a}}$

\begin{tabular}{lccc}
\hline Chemical name & Source & Provided purity $^{\mathrm{b}}$ & Purification method $^{\text {Air Products }}$ \\
\hline Methane & White Martins & $>0.995$ & None \\
Carbon dioxide & Whe.998 & None \\
\hline
\end{tabular}

${ }^{a}$ All the purities of the samples were obtained by the certificates of their suppliers, and no further purity measurements were performed.

${ }^{\mathrm{b}}$ Weight fraction.

Table 2. Composition of dead oil.

\begin{tabular}{lccccc}
\hline Compound & Weight $\%$ & $M\left(\mathrm{~g} \mathrm{~mol}^{-1}\right)$ & Compound & Weight $\%$ & $M\left(\mathrm{~g} \mathrm{~mol}^{-1}\right)$ \\
\hline $\mathrm{C}_{3}$ & 0.01 & 44 & $\mathrm{C}_{16}$ & 2.67 & 222 \\
$i \mathrm{C}_{4}$ & 0.03 & 58 & $\mathrm{C}_{17}$ & 2.59 & 237 \\
$n \mathrm{C}_{4}$ & 0.07 & 58 & $\mathrm{C}_{18}$ & 2.88 & 251 \\
$i \mathrm{C}_{5}$ & 0.16 & 72 & $\mathrm{C}_{19}$ & 2.90 & 2.7 \\
$n \mathrm{C}_{5}$ & 0.20 & 72 & $\mathrm{C}_{20}$ & 2.32 & 275 \\
$\mathrm{C}_{6}$ & 1.80 & 84 & $\mathrm{C}_{21}$ & 2.29 & 305 \\
$\mathrm{BTX}^{\mathrm{a}}$ & 0.56 & - & $\mathrm{C}_{22}$ & 2.19 & 318 \\
$\mathrm{C}_{7}$ & 2.25 & 96 & $\mathrm{C}_{23}$ & 2.21 & 331 \\
$\mathrm{C}_{8}$ & 2.11 & 107 & $\mathrm{C}_{24}$ & 2.14 & 355 \\
$\mathrm{C}_{9}$ & 2.42 & 121 & $\mathrm{C}_{25}$ & 2.17 & 374 \\
$\mathrm{C}_{10}$ & 2.75 & 134 & $\mathrm{C}_{26}$ & 1.75 & 388 \\
$\mathrm{C}_{11}$ & 2.79 & 147 & $\mathrm{C}_{27}$ & 2.00 & 4.70 \\
$\mathrm{C}_{12}$ & 2.85 & 161 & $\mathrm{C}_{28}$ & 40.22 & - \\
$\mathrm{C}_{13}$ & 3.16 & 175 & $\mathrm{C}_{29}$ & & \\
$\mathrm{C}_{14}$ & 2.96 & 190 & & & \\
$\mathrm{C}_{15}$ & 3.15 & 206 & & & \\
\hline
\end{tabular}

${ }^{a}$ Benzene, toluene and xylenes.

combined expanded uncertainty, $\mathrm{U}_{c}(k=2)$, in the composition of the mixture is $1 \times 10^{-4}$ in weight fraction.

A second sample was prepared using a subsample of the RLO. Firstly, a second cylinder was connected to the first one by the sample side by a system of tubes and valves under a vacuum. The volumetric pump was used to control the flow and keep the pressure constant at $40 \mathrm{MPa}$ during the sample transfer. After the subsampling has finished, an additional $13 \mathrm{wt} \% \mathrm{CO}_{2}$ was injected into the second sample using the same procedure abovementioned. The second sample was also agitated in the rocker for $24 \mathrm{~h}$ at $40 \mathrm{MPa}$. The compositions of the mixtures studied in this work are given in Table 3. After shaking, the cylinders were weighed again to ensure that there were no leakage losses.

\subsection{Density measurements}

The densities of the samples were measured by using a U-shaped vibrating tube densitometer Anton Paar DMA HPM, with a mPDS-5 evaluation unit as the reading device. In addition to the densitometer, the experimental setup includes one volumetric pump (Quizix Q5000) required to control the pressure in the measurement cell and a pressure transducer (AST 4300) which measures pressures up to $138 \mathrm{MPa}$ with a standard uncertainty of $0.35 \mathrm{MPa}$. The measuring cell of the densitometer is maintained at a constant temperature through a liquid circulator bath Julabo 300F. The temperature is measured by a builtin temperature sensor. According to the manufacturer's specification, the temperature error is less than $0.1 \mathrm{~K}$, and according to our measurements, the standard uncertainty $u(T)$ is $0.02 \mathrm{~K}$. A schematic of the experimental apparatus can be found in Figure 1. The pressurized sample was charged into the densitometer, purging four times the volume of the tube to ensure that the sample composition in the measuring cell is the same as that prepared in the sample cylinder.

The calibration of the densitometer was performed following a modification of the Lagourette et al. [56] method, in an analogous way to that described by Comuñas et al. [57] by using vacuum and Milli-Q water as references. The density values of water were obtained from the Equation of State (EoS) proposed by Wagner and Pruss 
Table 3. Composition in weight $\left(x_{w}\right)$ and mole $\left(x_{m}\right)$ fraction of the Recombined Live Oil (RLO), and its mixture with additional $\mathrm{CO}_{2}$.

\begin{tabular}{lcccr}
\hline Compound & \multicolumn{2}{c}{ RLO } & \multicolumn{2}{c}{$\mathrm{RLO}+\mathrm{CO}_{2}(87.28: 12.72) \mathrm{w} / \mathrm{w}$} \\
\cline { 2 - 4 } & $\left(x_{w}\right)$ & $\left(x_{m}\right)$ & $\left(x_{w}\right)$ & $\left(x_{m}\right)$ \\
\hline Dead oil & 0.812 & 0.333 & 0.707 & 0.237 \\
Methane & 0.033 & 0.248 & 0.029 & 0.177 \\
Carbon dioxide & 0.154 & 0.419 & 0.264 & 0.586 \\
\hline
\end{tabular}

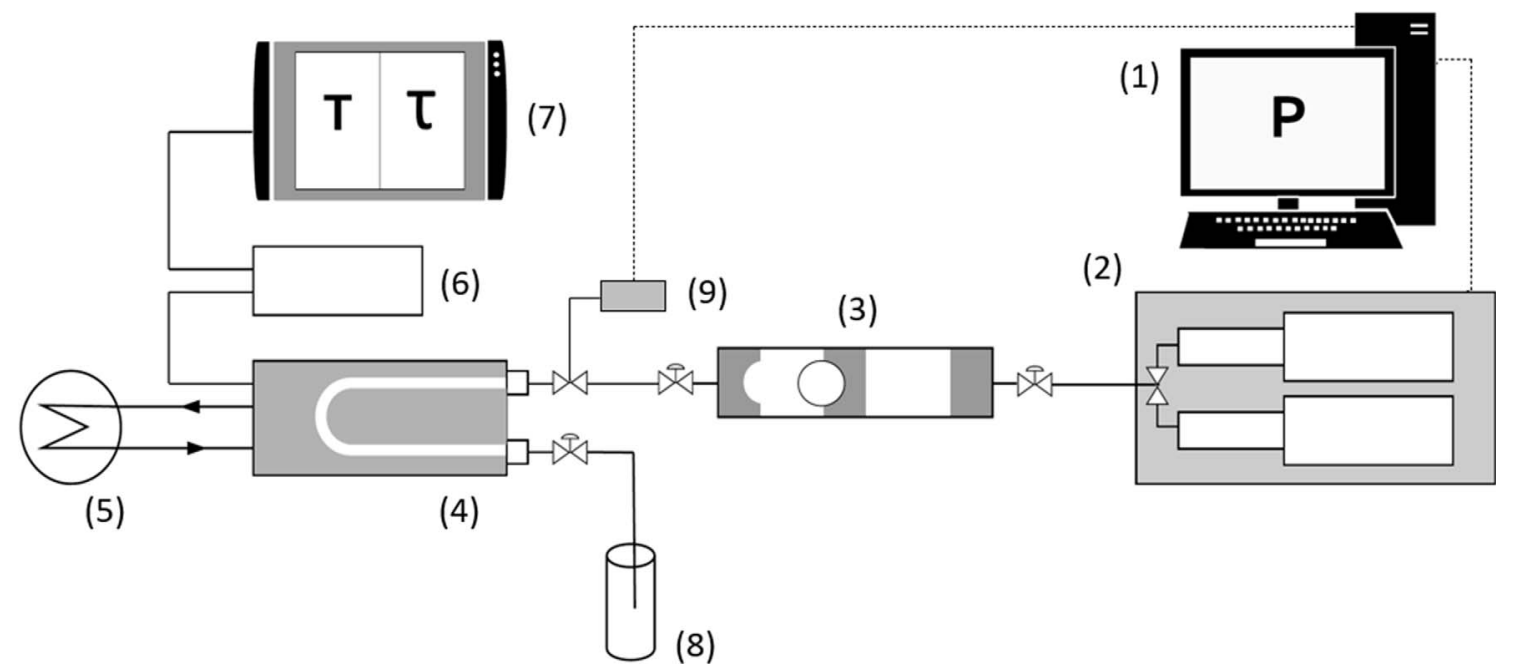

Fig. 1. Schematic of the densitometer. 1 - Computer, 2 - Quizix pump Q5000, 3 - Sample cylinder, 4 - DMA HPM, 5 - Julabo 300F thermostatic bath, 6 - HPM DMA interface module, 7 - mPDS-5 evaluation unit, 8 - Cylinder sample receiver, 9 - Pressure transducer.

[58]. For the liquid phase, the uncertainty in density of this EoS is $0.0001 \%$ at $0.1 \mathrm{MPa}$, and $0.003 \%$ at pressures in the interval from (10 to 100) $\mathrm{MPa}$ and temperatures up to $423 \mathrm{~K}$. Thus, following Lagourette's method and the Comunas' proposal, the densities were obtained according to equation (1). Density measurements were performed in the range of pressures from (27.6 to 68.9) $\mathrm{MPa}$ and at (333.15 and 353.15$) \mathrm{K}$. Considering the propagation error law, the combined expanded uncertainty $\mathrm{U}_{c}(k=2)$ for density measurements of all systems evaluated in this study is $\mathrm{U}_{c}(\rho)=0.33 \mathrm{~kg} \mathrm{~m}^{-3}$ :

$$
\begin{aligned}
& \rho_{\text {oil }}(T, P)=\rho_{\text {water }}(T, P) \\
& \quad+\rho_{\text {water }}(T, 0.1 \mathrm{MPa})\left[\frac{\tau_{\text {oil }}^{2}(T, P)-\tau_{\text {water }}^{2}(T, P)}{\tau_{\text {water }}^{2}(T, 0.1 \mathrm{MPa})-\tau_{\text {vacuum }}^{2}(T)}\right],
\end{aligned}
$$

where $\rho$ is the density in $\mathrm{kg} \mathrm{m}^{-3}$ and $\tau$ is the oscillation period in $\mu \mathrm{s}$.

The densities of pure $\mathrm{CO}_{2}$ (used to calculate mixing rules based on kinematic viscosity) were calculated with the equation of state developed by Span and Wagner [59]. The estimated uncertainty claimed by the authors in the original source ranges from $0.03 \%$ to $0.05 \%$ in density at the pressure and temperature ranges addressed in this study.

\subsection{Viscosity measurements}

A modified Hagen-Poiseuille equation [60] is used to obtain the experimental dynamic viscosity by a capillary viscometer, as follows:

$$
\mu=K_{v} \frac{\pi r^{4} \Delta P}{8 Q L},
$$

where $\mu$ is the dynamic viscosity in $\mathrm{cP}, \Delta P$ is the differential pressure in $\mathrm{MPa}, r$ is the tube radius in $\mathrm{cm}$ $(0.01905 \mathrm{~cm}), Q$ is the volumetric flow rate in $\mathrm{cm}^{3} \mathrm{~s}^{-1}$, $L$ is the length of the capillary tube in $\mathrm{cm}(365.76 \mathrm{~cm})$, and $K_{v}$ is the calibration factor (1.13).

The calibration factor $K_{v}$ of the viscometer was experimentally determined by calibrating it using viscosity standards supplied by Cannon Instruments. The capillary tube was calibrated from (293 to 413) K, and the accuracy of the measurements was determined as $3 \%$.

The viscosity measurements were performed in a PVT cell (Chandler 3000). The system is equipped with two transfer vessels (called pump cell and mini cell) with effective volumes of $400 \mathrm{~cm}^{3}$ and $100 \mathrm{~cm}^{3}$, respectively. The vessels are connected through a capillary tube in a temperaturecontrolled oven, as shown in Figure 2. The pump cell has a motorized piston-driven system that transfers the 


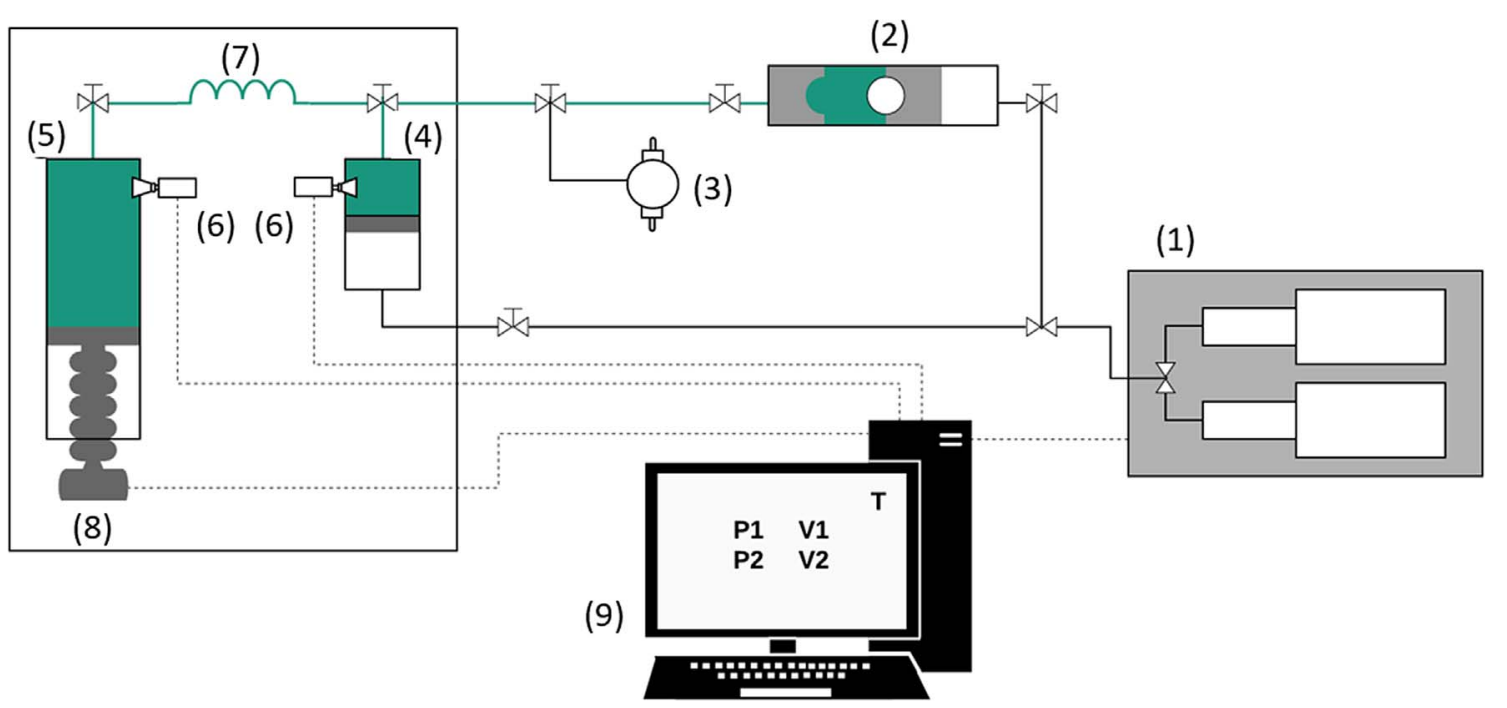

Fig. 2. Schematic of the capillary viscometer. 1 - Quizix pump Q6000, 2 - Sample Cylinder, 3 - Vacuum pump, 4 - Minicell, 5 Pump cell, 6 - Pressure transducers, 7 - Capillary tube, 8 - Motorized piston, 9 - Computer.

controlled flow rate from the pump to the sample contained in the transfer vessels. A return line of the hydraulic oil connecting the mini cell to a volumetric pump (Quizx Q6000) controls the pressure in the system. Two AST 4300 pressure transducers, which measure pressures up to $138 \mathrm{MPa}$ with a standard uncertainty of $0.35 \mathrm{MPa}$, were used to monitor the pressure. The temperature of the oven is controlled by an air bath within $\pm 0.05 \mathrm{~K}$ of the measurement temperature. The sample was pumped from the pump cell to the mini cell through the capillary tube with a known flow rate while the pressure was recorded by the transducers. The average of the pressure values provided by the transducers is considered as the nominal pressure of the system. Six viscosity measurements were performed for each experimental condition. The maximum standard deviation related to these measurements was equal to $0.01 \mathrm{cP}$.

\subsection{Mixing rules of viscosity}

Thirteen mixing rules were evaluated in this study. These mixing rules are classified into three different categories: pure mixing rules, mixing rules with viscosity blending index, and mixing rules with additional parameters. This classification is already described elsewhere [32, 34], therefore, they will be only briefly presented here in the topics (a) to (c) as follows:

(a) Pure mixing rules. They only require experimental viscosity of components and composition of mixtures in terms of volume, weight, or molar fractions. The tested rules of this type are Arrhenius [22], Bingham [23], Kendall and Monroe [24], linear, Cragoe [27], Chirinos [28], and Double-log [29].

(b) Mixing rules with viscosity blending index. They involve the determination of the Viscosity Blending Index. The tested rules of this type are Chevron [31] and Refutas index method [30]. (c) Mixing rules with additional parameters. The calculation of extra-parameters is necessary. These parameters are obtained from correlations related to the density and kinematic viscosity or from fitting parameters. The tested rules of this type are Lederer [25], Lobe [61], Latour [28], and Power law [32]. The mixing rule proposed by Lederer was also used with a predictive scheme by calculating parameter $\alpha$ as proposed by Shu [26].

Tables 4-6 list the pure mixing rules, the mixing rules with additional parameters, and the mixing rules with the blending index, respectively. The mixing rules are weighted by the molar $(m)$, volumetric $(\mathrm{v})$, or weight $(w)$ fractions of the mixture components.

Shu [26] developed a predictive scheme for calculating the term $\alpha$ found in the Lederer method [25] (see Tab. 5) based on the density and viscosity of the liquids in the binary mixture as follows:

$$
\alpha=\frac{17.04 \Delta \rho^{0.5237} \rho_{i}^{3.2745} \rho_{j}^{1.6316}}{\ln \left(\mu_{i} / \mu_{j}\right)},
$$

where $\Delta \rho=\rho_{i}-\rho_{j}$.

For convenience, in the original source, $i$ was designated for the more viscous component (the oil) and $j$ for the less viscous one (the solvent). In his study, Shu [26] was interested in mixtures with viscosity ratios $\left(\mu_{i} / \mu_{j}\right)$ of $10^{3}$ or higher. In this context, the most common situation is that $\rho_{i} \gg \rho_{j}$, therefore, the term $\Delta \rho$ is always positive. However, for some correlating conditions of pressure and temperature addressed in this study, the $\mathrm{CO}_{2}$ density (the solvent) is higher than that of the live oil density, which would make the $\Delta \rho$ negative and the $\alpha$ calculation undefined. Thus, in this study, we proposed $\Delta \rho$ to be calculated as the module $\left|\rho_{i}-\rho_{j}\right|$, thus, preventing the term delta from being undefined. 
Table 4. Pure mixing rules for a binary mixture of compounds $i$ and $j$.

\begin{tabular}{lc}
\hline Mixing rule & Equation \\
\hline Arrhenius & $\mu=\mu_{i}^{v_{i}} \mu_{j}^{v_{j}}$ \\
Bingham & $\frac{1}{\mu}=\frac{v_{i}}{\mu_{i}}+\frac{v_{j}}{\mu_{j}}$ \\
Kendall and Monroe & $\mu^{1 / 3}=w_{i} \mu_{i}^{1 / 3}+w_{j} \mu_{j}^{1 / 3}$ \\
Linear & $\mu=\mathrm{v}_{i} \mu_{i}+\mathrm{v}_{j} \mu_{j}$ \\
Cragoe & $\frac{1}{\ln (2000 \mu)}=\frac{w_{i}}{\ln \left(2000 \mu_{i}\right)}+\frac{w_{j}}{\ln \left(2000 \mu_{j}\right)}$ \\
Chirinos & $\log \log (v+0.7)=w_{i} \log \log \left(v_{i}+0.7\right)+w_{j} \log \log \left(v_{j}+0.7\right)$ \\
Double $\log$ & $\ln \ln (\mu+1)=w_{i} \ln \ln \left(\mu_{i}+1\right)+w_{j} \ln \ln \left(\mu_{j}+1\right)$
\end{tabular}

$v=$ kinematic viscosity.

Table 5. Mixing rules with additional parameters for a binary mixture of compounds $i$ and $j$.

\begin{tabular}{|c|c|}
\hline Mixing rule & Equation \\
\hline \multirow[t]{3}{*}{ Lederer } & $\ln \mu=x_{i}^{\prime} \ln \mu_{i}+x_{j}^{\prime} \ln \mu_{j}$ \\
\hline & $x^{\prime}{ }_{j}=1-x^{\prime}{ }_{i \text { and }} x^{\prime}{ }_{i}=\frac{\alpha v_{i}}{\alpha v_{i}+v_{j}}$ \\
\hline & $\frac{\mu}{\mu_{j}}-1=\left[\alpha \ln \left(\frac{\mu_{i}}{\mu_{j}}\right)\right] \mathrm{v}_{i}$ \\
\hline \multirow[t]{3}{*}{ Latour } & $v=e^{\left(e\left[a\left(1-w_{j}^{n}\right)\right]+\ln v_{j}-1\right)}$ \\
\hline & $a=\ln \left(\ln v_{i}-\ln v_{j}+1\right)$ \\
\hline & $n=\frac{v_{j}}{0.9029 v_{j}+0.1351}$ \\
\hline \multirow[t]{4}{*}{ Lobe } & $v=\phi_{i} v_{i} e^{\phi_{j} \alpha_{j}}+\phi_{j} v_{j} e^{\phi_{i} \alpha_{i}}$ \\
\hline & $\alpha_{i}=-1.7 \frac{\ln v_{i}}{v_{i}}$ \\
\hline & $\alpha_{j}=0.27 \ln \frac{v_{j}}{v_{i}}+\left(1.3 \ln \frac{v_{j}}{v_{i}}\right)^{1 / 2}$ \\
\hline & $\phi_{i}=\frac{m_{i} V_{i}}{m_{i} V_{i}+m_{j} V_{j}}$ and $\phi_{j}=\frac{m_{j} V_{j}}{m_{i} V_{i}+m_{j} V_{j}}$ \\
\hline Power Law & $\mu=\left(w_{i} \mu_{i}^{n}+w_{j} \mu_{j}^{n}\right)^{1 / n}$ \\
\hline
\end{tabular}

$\phi=$ liquid molar volume fraction. $V=$ molar volume.

\section{Results and discussion}

\subsection{Experimental density}

The density measurements for the RLO and its mixture with additional $\mathrm{CO}_{2}$ were performed along two isotherms,

Table 6. Mixing rules with blending index for a binary mixture of compounds $i$ and $j$.

\begin{tabular}{lc}
\hline Mixing rule & Equation \\
\hline Chevron & $\mathrm{VBI}_{i}=\frac{\log v_{i}}{3+\log v_{i}}$ \\
$\mathrm{VBI}_{\beta}=\sum_{i=1}^{n} v_{i} \mathrm{VBI}_{i}$ \\
$\mu=10^{\left(\frac{3 \mathrm{VBI}_{\beta}}{1-\mathrm{VBI}_{\beta}}\right)}$
\end{tabular}

Refutas index method

(333.15 and 353.15) K, for pressures ranging from (27.6 to 68.9) $\mathrm{MPa}$. The minimum pressures of the measurements were set to values higher than the saturation pressures of the samples. The saturation points were obtained experimentally in the PVT cell by which it is possible to visualize the formation of bubbles through a sapphire window. The maximum saturation pressure was $26.5 \mathrm{MPa}$ concerning $\mathrm{RLO}+\mathrm{CO}_{2}(87.28: 12.72) \mathrm{w} / \mathrm{w}$ at $353.15 \mathrm{~K}$. The measured densities for the two mixtures are presented in Table 7 . These values are also illustrated in Figure 3 as a function of pressure for the two isotherms.

The experimental density obtained in this study for the RLO and RLO $+\mathrm{CO}_{2}$ systems, which are shown in Figure 3, presented a well-known trend along the isotherms, i.e., densities increased with the increase of pressure along each isotherm. Furthermore, it is also possible to note the 
Table 7. Experimental densities, $\rho / \mathrm{kg} \mathrm{m}^{-3}$, for the Recombined Live Oil (RLO) and its mixture with $\mathrm{CO}_{2}(87.28: 12.72)$ $\mathrm{w} / \mathrm{w}$.

\begin{tabular}{|c|c|c|c|c|}
\hline \multirow[t]{2}{*}{$P(\mathrm{MPa})$} & \multicolumn{2}{|c|}{ RLO } & \multicolumn{2}{|c|}{$\mathrm{RLO}+\mathrm{CO}_{2}(87.28: 12.72) \mathrm{w} / \mathrm{w}$} \\
\hline & $T=333.15 \mathrm{~K}$ & $T=353.15 \mathrm{~K}$ & $T=333.15 \mathrm{~K}$ & $T=353.15 \mathrm{~K}$ \\
\hline 27.6 & 833.1 & 816.8 & 845.2 & 826.3 \\
\hline 34.5 & 839.6 & 824.0 & 852.6 & 834.5 \\
\hline 41.4 & 845.5 & 830.6 & 859.7 & 842.4 \\
\hline 48.3 & 851.0 & 836.5 & 866.3 & 849.6 \\
\hline 55.2 & 856.1 & 841.8 & 872.3 & 856.2 \\
\hline 62.1 & 860.9 & 847.1 & 877.6 & 862.2 \\
\hline 68.9 & 865.4 & 852.2 & 883.0 & 868.0 \\
\hline
\end{tabular}

Standard uncertainties are $u(T)=0.02 \mathrm{~K}$ and $u(P)=0.35 \mathrm{MPa}$. The combined expanded uncertainty is $U_{c}(\rho)=$ $0.33 \mathrm{~kg} \mathrm{~m}^{-3}$ with 0.95 level of confidence $(k=2)$.

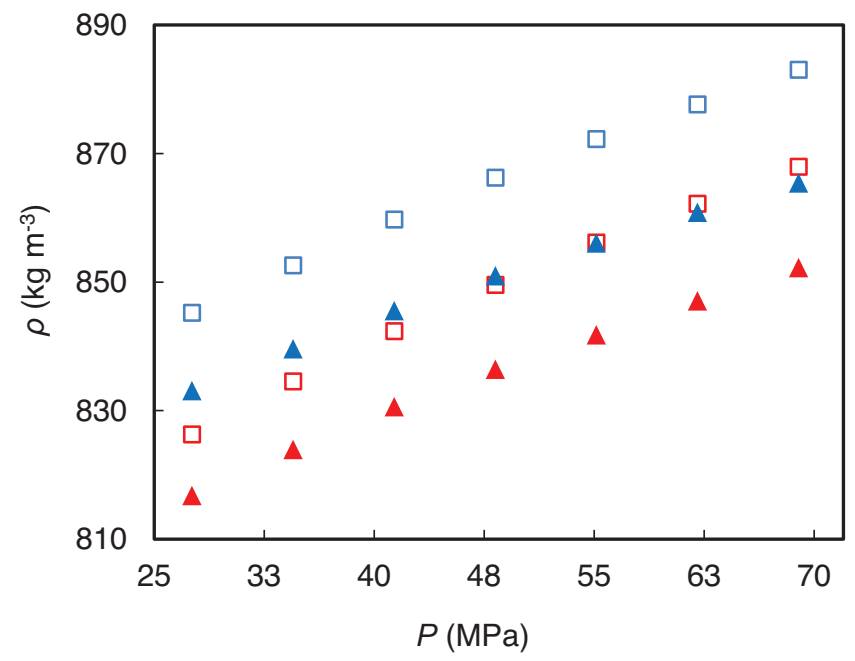

Fig. 3. Density, $\rho$, of the $(\boldsymbol{\Delta})$ RLO and $(\square) \mathrm{RLO}+\mathrm{CO}_{2}$ (87.28:12.72) w/w. (Blue) $333.15 \mathrm{~K}$, and (red) $353.15 \mathrm{~K}$.

crossing of the isopleths of the different systems around $50 \mathrm{MPa}$. This effect can be attributed to the compressibility effects of fluid components, where the compressibility of $\mathrm{CO}_{2}$ is higher than that of most hydrocarbons at the studied temperatures and pressures. Therefore, the higher the concentration of $\mathrm{CO}_{2}$, the more noticeable the dependence of density on pressure becomes, causing the slope of the mixture density versus pressure to become more pronounced, then causing the crossing of the isopleths. This effect has already been reported for mixtures of $\mathrm{CO}_{2}+$ hydrocarbons [62-65], and also for mixtures of hydrocarbons with gases other than $\mathrm{CO}_{2}$, such as methane [66, 67].

\subsection{Volume change on mixing and excess volume}

Mixture densities can be predicted by the assumption of no volume change on mixing as follows:

$$
\rho_{\text {ideal,mix }}=\left(\frac{w_{\mathrm{RLO}}}{\rho_{\mathrm{RLO}}}+\frac{w_{\mathrm{CO}_{2}}}{\rho_{\mathrm{CO}_{2}}}\right)^{-1},
$$

where $w$ is the weight fraction and $\rho$ is the density of the liquids in the mixture. The subscript "ideal,mix" means the ideal property of mixture.

Equation (4) predicts the experimental density presented in Table 7 with $1.1 \%$ AAD (Eq. (5)) and a maximum absolute deviation of $23.3 \mathrm{~kg} \mathrm{~m}^{-3}$. The densities of pure $\mathrm{CO}_{2}$ were calculated by EoS of Span and Wagner [59], which provides uncertainty in density up to $\pm 0.05 \%$ at the conditions of temperature and pressure of this study. In fact, the properties of mixtures are relatively different from the properties of the substances comprising the mixtures. The total volume of the mixture may increase or decrease during mixing. Thus, the difference between the value of the experimental density of the mixture and the value obtained from equation (4) may indicate the measure of the deviation from the ideal behavior of mixture. In this study, in order to assess the effect of pressure and temperature on the ideal behavior of the mixing density, the dimensionless parameter, $\Delta V / V$, as reported by Nourozieh et al. [29, 33], was used according to equation (6):

$$
\begin{gathered}
\mathrm{AAD}=\frac{100}{N} \sum_{i=1}^{N}\left|\frac{\rho_{i}^{\text {exp }}-\rho_{i}^{\text {calc }}}{\rho_{i}^{\text {exp }}}\right|, \\
\frac{\Delta V}{V}=\frac{\frac{1}{\rho_{\text {mix.exp }}}-\left(\frac{w_{\mathrm{RLO}}}{\rho_{\mathrm{RLO}}}+\frac{w_{\mathrm{CO}_{2}}}{\rho_{\mathrm{CO}_{2}}}\right)}{\frac{w_{\mathrm{RLO}}}{\rho_{\mathrm{RLO}}}+\frac{w_{\mathrm{CO}_{2}}}{\rho_{\mathrm{CO}_{2}}}},
\end{gathered}
$$

where the ratio $\Delta V / V$ is the volume change on mixing.

Although the effect of pressure on the volume change during mixing of the bitumen + solvent systems was moderate at the same temperatures and dilution ratio addressed in this study (maximum of $|\Delta V / V| \approx 0.01$ ) (Nourozieh et al. [29, 33]), Figure 4 shows that this effect is significant for the live oil $+\mathrm{CO}_{2}$ systems, reaching $|\Delta V / V| \approx 0.03$ at $353.15 \mathrm{~K}$. The absolute values of $\Delta \mathrm{V} / V$ increase with increasing temperature and decrease with increasing pressure. They are all negative over the whole pressure range. The negative $\Delta V / V$ might result mainly from the effects of free volume caused by the interstitial accommodation of the shorter molecules in the structure of the longer chain 


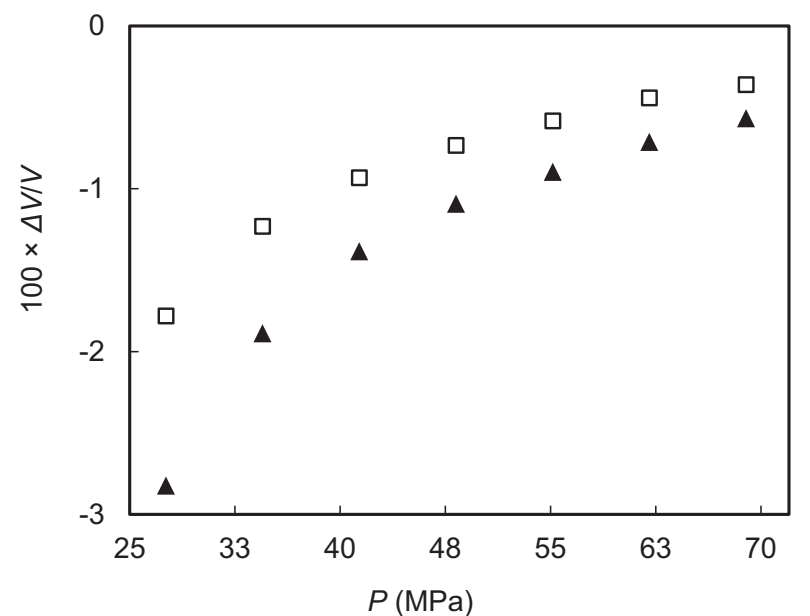

Fig. 4. Volume change on mixing for the $\mathrm{RLO}+\mathrm{CO}_{2}$ $(87.28: 12.72) \mathrm{w} / \mathrm{w}$ mixture at $(\square) 333.15 \mathrm{~K}$ and $(\boldsymbol{\Delta}) 353.15 \mathrm{~K}$ in a function of pressure.

hydrocarbons, which leads to a more compact and less compressible system $[62,63]$. It is worth noting that large negative $\Delta V / V$ values can result from the condensation of gas or supercritical $\mathrm{CO}_{2}$ into the crude oil. The magnitude of this contribution depends on the extent of the gas-like behavior of the supercritical $\mathrm{CO}_{2}$, which becomes more important when pressure decreases and temperature increases. However, the increasing pressure leads to a decrease in the mean intermolecular distances causing the increase in $\Delta V / V$ values, and hence the decrease in the absolute values of $\Delta V / V$.

The trends in the results presented in Figure 4 are in full agreement with those reported by Nourozieh et al. [29, 33] who also reported negative $\Delta V / V$ for bitumen + light hydrocarbon systems at temperatures ranging from 295 up to $463 \mathrm{~K}$ and at pressures up to $10 \mathrm{MPa}$. However, for hydrocarbon $+\mathrm{CO}_{2}$ systems, the $\Delta V / V$ ratio could assume both positive and negative values. The literature shows that positive values are generally observed at pressure typically above $40 \mathrm{MPa}[53,54,64,65]$.

It is worth mentioning that the sign of the $\Delta V / V$ ratio follows the same values that the excess molar volume $\left(V^{\mathrm{E}}\right)$ would present. Therefore, a strictly analogous discussion in terms of $V^{\mathrm{E}}$ could be carried out for the results shown in Figure 4. However, due to the uncertainties associated with the oil composition, the proposal presented by Nourozieh et al. [29, 33] becomes more convenient, as it does not require any information related to the molar composition. On the other hand, this information is indispensable for calculating $V^{\mathrm{E}}$.

Since the volume change on mixing varied significantly with pressure and temperature due to the injection of $\mathrm{CO}_{2}$ into the live oil, the simplification presented in equation (4) to predict mixture densities can lead to large deviations. However, the deviations in density prediction

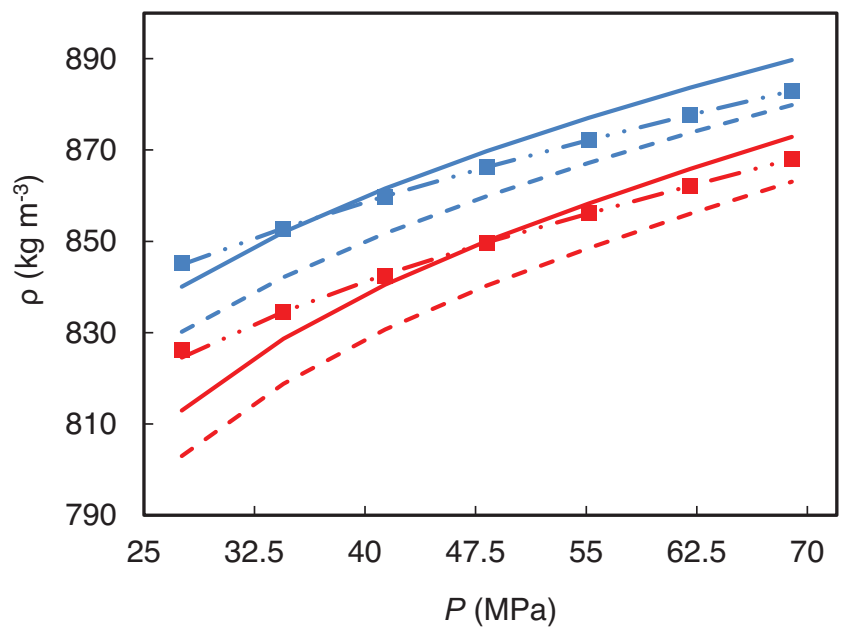

Fig. 5. Density of the RLO $+\mathrm{CO}_{2}(87.28: 12.72) \mathrm{w} / \mathrm{w}$ mixture at $333.15 \mathrm{~K}$ (blue) and $353.15 \mathrm{~K}$ (red). (ם) Experimental values, $(---) \rho_{\text {ideal,mix }},\left(\right.$ Eq. (4)), $(-\cdot-) \rho_{\text {excess }}$ (calculated from Eqs. (7) and (8), and (-) $\rho_{\text {excess }}$ (Eq. (7) and $\beta_{i j}$ as a single-parameter equal to 0.0526$)$.

can be mitigated using the excess volume approach as also presented by Nourozieh et al. [29, 33], according to equation (7):

$$
\begin{aligned}
\frac{1}{\rho_{\text {excess }}}= & \frac{w_{\mathrm{CO}_{2}}}{\rho_{\mathrm{CO}_{2}}}+\frac{1-w_{\mathrm{CO}_{2}}}{\rho_{\text {l.o. }}} \\
& -w_{\mathrm{CO}_{2}}\left(1-w_{\mathrm{CO}_{2}}\right)\left(\frac{1}{\rho_{\mathrm{CO}_{2}}}+\frac{1}{\rho_{\text {l.o. }}}\right) \beta_{i j},
\end{aligned}
$$

where $\rho_{\text {excess }}$ is the density calculated using the excess volume approach, and $\beta_{i j}$ is a binary coefficient.

Nourozieh and co-workers reported $\beta_{i j}$ as a singleparameter to correlated the densities of the binary mixtures of pentane + bitumen [33] and heptane + bitumen [29]. However, the densities calculated with equation (7) using $\beta_{i j}$ as a single-parameter resulted in an under-prediction of the measured data presented in Table 7 . In the present study, this parameter was considered a function of pressure and temperature with four adjustable parameters. The best-fitted binary parameter $\left(\beta_{i j}\right)$ was achieved through a double linear function of the reciprocal of pressure and temperature, according to equation (8):

$$
\beta_{i j}=k_{1}+k_{2} T^{-1}+\left(k_{3}+k_{4} T^{-1}\right) P^{-1},
$$

where the values of the fitting parameters $k_{1}$ to $k_{4}$ are $0.1415,39.1406 \mathrm{~K}, 22.9166 \mathrm{MPa}$, and $-6.7015 \times$ $10^{-3} \mathrm{~K} \mathrm{MPa}$, respectively.

The correlative capability of equation (8) can be clearly observed since the measured density data are represented with $0.03 \% \mathrm{AAD}$, and a maximum absolute deviation of $1.76 \mathrm{~kg} \mathrm{~m}^{-3}$. Figure 5 shows the correlated densities along with the experimental values using equations (4) and (8), as well as considering $\beta_{i j}$ as a single-parameter. 
Table 8. Measured dynamic viscosities, $\mu / \mathrm{cP}$, of the Recombined Live Oil (RLO) and its mixture with $\mathrm{CO}_{2}$ at pressure $P$ and temperature $T$.

\begin{tabular}{|c|c|c|c|c|}
\hline \multirow[t]{2}{*}{$P(\mathrm{MPa})$} & \multicolumn{2}{|c|}{$\mathrm{RLO}$} & \multicolumn{2}{|c|}{$\mathrm{RLO}+\mathrm{CO}_{2}(87.28: 12.72) \mathrm{w} / \mathrm{w}$} \\
\hline & $T=333.15 \mathrm{~K}$ & $T=353.15 \mathrm{~K}$ & $T=333.15 \mathrm{~K}$ & $T=353.15 \mathrm{~K}$ \\
\hline 27.6 & 2.11 & 1.62 & 1.31 & 0.99 \\
\hline 34.5 & 2.26 & 1.75 & 1.35 & 1.02 \\
\hline 41.4 & 2.38 & 1.81 & 1.42 & 1.09 \\
\hline 48.3 & 2.57 & 1.93 & 1.49 & 1.15 \\
\hline 55.2 & 2.72 & 2.03 & 1.58 & 1.19 \\
\hline 62.1 & 2.86 & 2.13 & 1.66 & 1.25 \\
\hline 68.9 & 3.17 & 2.38 & 1.81 & 1.39 \\
\hline
\end{tabular}

Standard uncertainties are $u(T)=0.05 \mathrm{~K}$ and $u(P)=0.35 \mathrm{MPa}$. The estimated accuracy of viscosity measurement is $0.03 \mu$.

\subsection{Experimental Viscosity}

Table 8 presents the dynamic viscosity obtained experimentally through the capillary viscometer using equation (2) for the RLO and its mixture with $\mathrm{CO}_{2}(87.28: 12.72) \mathrm{w} / \mathrm{w}$. These values are also illustrated in Figure 6. The addition of $\mathrm{CO}_{2}$ to the RLO has been found to reduce the viscosity of the resulting mixture. This effect is well known and followed the trend observed in other systems involving hydrocarbons and gases [46, 68-69]. In these experiments, the effects of temperature, pressure, and $\mathrm{CO}_{2}$ addition on the viscosity were evaluated. It was found that the impact of temperature on viscosity is similar in the two systems. The increase in temperature from (333.15 to 353.15$) \mathrm{K}$ caused an average decrease of $24 \%$ in viscosity, with a maximum of $25 \%$ and a minimum of $22 \%$. Furthermore, diluting the live oil with $\mathrm{CO}_{2}$ significantly reduces the viscosity of the mixture ( $41 \%$ on average), while the viscosities increased with increasing pressure. The effect of pressure on viscosity is higher for the RLO than for its mixture with $\mathrm{CO}_{2}$, regardless of the temperature. For instance, the increase in viscosity of the RLO and the $\mathrm{RLO}+\mathrm{CO}_{2}$ (87.28:12.72) w/w mixture in the pressure range evaluated were $50 \%$ and $38 \%$ at $333.15 \mathrm{~K}$, respectively. At $353.15 \mathrm{~K}$, those numbers are $47 \%$ and $40 \%$, respectively.

\subsection{Comparison of mixing rules}

For the purpose of comparing the experimental viscosity values with those obtained with the mixing rules, the Absolute Average Deviation (AAD) (analogously to Eq. (5)), the Maximum Deviation (MD), the Standard Deviation $(\sigma)$ and the Residual $(R)$ are calculated and defined as follows:

$$
\begin{aligned}
\mathrm{MD} & =\max \left(100\left|\frac{\mu_{i}^{\exp }-\mu_{i}^{\text {calc }}}{\mu_{i}^{\exp }}\right|\right), \\
\sigma & =\sqrt{\frac{\sum_{i=1}^{N}\left(\mu_{i}^{\exp }-\mu_{i}^{\text {calc }}\right)^{2}}{N-p}},
\end{aligned}
$$

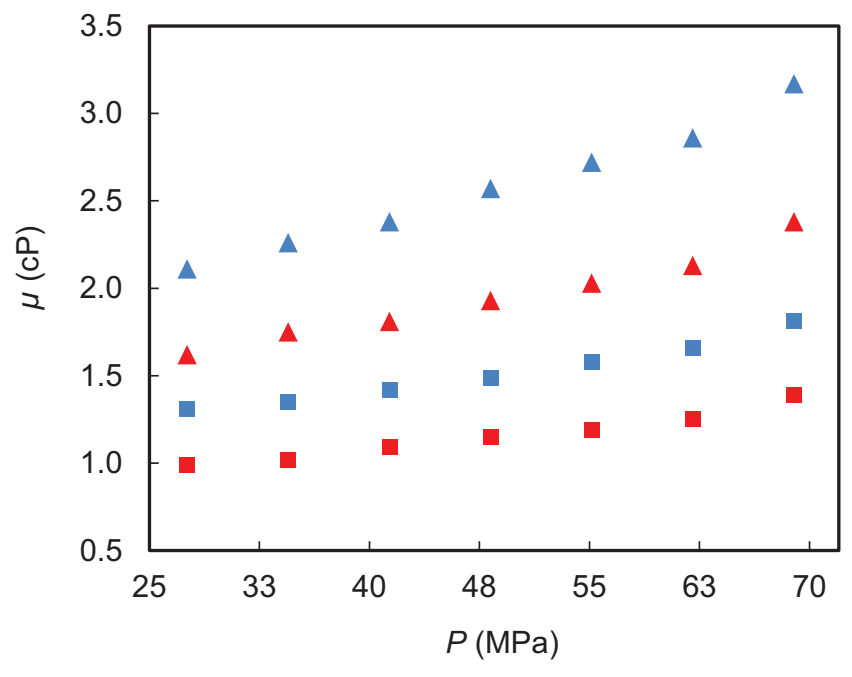

Fig. 6. Experimental dynamic viscosity of the RLO and its mixture with $\mathrm{CO}_{2}$ in a function of pressure. $(\mathbf{\Delta}) \mathrm{RLO}$ and ( $\mathrm{RLO}+\mathrm{CO}_{2}$ mixture $(87.28: 12.72) \mathrm{w} / \mathrm{w}$. (Blue) $333.15 \mathrm{~K}$ and (red) $353.15 \mathrm{~K}$.

$$
R_{\mathrm{i}}=\mu_{\mathrm{i}}^{\exp }-\mu_{\mathrm{i}}^{\text {calc }},
$$

where $p$ is the number of fitting parameters. The residual $R$ will be used as $R_{+}$or $R_{-}$to indicate the sign of the difference shown in equation (11).

Table 9 summarizes the statistical parameters related to the 13 mixing rules evaluated in this study. For Arrhenius, Kendall and Monroe, Linear, Double Log, Chevron, Power law, and Lederer mixing rules, the results with different fractions (molar, volume, and weight) are also assessed. Thus, a total of 28 different forms to calculate the viscosities of the mixtures were tested. In Table 9 , the mixing rules are also represented by the abbreviation $M$. The viscosities of pure $\mathrm{CO}_{2}$ were calculated by the EoS of Fenghour et al. [70]. The uncertainties associated with this equation are up to $\pm 5 \%$, according to the authors.

As expected, there were large variations on the predicted viscosity depending on the equation used. Among 
Table 9. Statistical analysis of the mixing rules.

\begin{tabular}{|c|c|c|c|c|c|c|}
\hline \multicolumn{2}{|c|}{ Mixing rule } & $\mathrm{AAD}(\%)$ & $M D(\%)$ & $\sigma(\mathrm{cP})$ & $R_{+}{ }^{\mathrm{a}}$ & $R_{-}{ }^{\mathrm{b}}$ \\
\hline \multicolumn{7}{|c|}{ Pure mixing rules } \\
\hline M1 & Arrhenius $(v)^{\mathrm{c}}$ & 14.4 & 21.3 & 0.22 & 0 & 14 \\
\hline M2 & Arrhenius $(w)^{\mathrm{d}}$ & 12.3 & 15.4 & 0.18 & 0 & 14 \\
\hline M3 & Arrhenius $(m)^{\mathrm{e}}$ & 32.0 & 38.1 & 0.43 & 14 & 0 \\
\hline M4 & Kendall and Monroe $(v)$ & 31.7 & 38.9 & 0.45 & 0 & 14 \\
\hline M5 & Kendall and Monroe $(w)$ & 30.2 & 34.3 & 0.42 & 0 & 14 \\
\hline M6 & Kendall and Monroe $(m)$ & 8.9 & 15.0 & 0.12 & 14 & 0 \\
\hline M7 & Linear $(v)$ & 49.4 & 56.3 & 0.69 & 0 & 14 \\
\hline M8 & Linear $(w)$ & 24.5 & 30.3 & 0.35 & 0 & 14 \\
\hline M9 & Linear $(m)$ & 50.9 & 58.6 & 0.71 & 0 & 14 \\
\hline M10 & Double Log $(v)$ & 8.3 & 12.4 & 0.13 & 2 & 12 \\
\hline M11 & Double Log $(w)$ & 6.2 & 9.9 & 0.09 & 1 & 11 \\
\hline M12 & Double Log $(m)$ & 26.1 & 32.0 & 0.36 & 14 & 0 \\
\hline M13 & Bingham & 148.6 & 159.2 & 2.03 & 0 & 14 \\
\hline M14 & Cragoe & 99.9 & 99.9 & 1.36 & 14 & 0 \\
\hline \multicolumn{7}{|c|}{ Mixing rules with blending index } \\
\hline M16 & Chevron $(v)$ & 10.8 & 16.4 & 0.17 & 2 & 12 \\
\hline M17 & Chevron $(w)$ & 7.7 & 12.1 & 0.11 & 0 & 14 \\
\hline M18 & Chevron $(m)$ & 49.9 & 54.9 & 0.68 & 14 & 0 \\
\hline \multicolumn{7}{|c|}{ Mixing rules with additional parameters } \\
\hline M20 & Power law $(v)^{\mathrm{f}^{\mathrm{f}}}$ & 4.7 & 13.8 & 0.08 & 7 & 7 \\
\hline M21 & Power law $(w)^{g}$ & 2.5 & 8.2 & 0.04 & 5 & 9 \\
\hline M22 & Power law $(m)^{\mathrm{h}}$ & 2.0 & 6.6 & 0.03 & 6 & 8 \\
\hline M23 & Lederer $(v)^{\mathrm{i}}$ & 2.0 & 5.8 & 0.03 & 6 & 8 \\
\hline M24 & Lederer $(w)^{\mathrm{j}}$ & 2.3 & 7.7 & 0.04 & 5 & 7 \\
\hline M25 & Lederer $(m)^{\mathrm{k}}$ & 2.3 & 5.9 & 0.04 & 7 & 7 \\
\hline M26 & Lederer/Shu ${ }^{\mathrm{l}}$ & 25.5 & 81.1 & 0.40 & 7 & 7 \\
\hline M27 & Lobe & 50.6 & 64.4 & 0.73 & 14 & 0 \\
\hline M28 & Latour & 70.2 & 75.7 & 0.95 & 14 & 0 \\
\hline
\end{tabular}

a) Number of positive Residuals (Eq. (11)). b) Number of negative Residuals (Eq. (11)). c) (v) Volume fraction. d) $(w)$ Composition in weight. e) ( $m$ ) Composition in mole. f) $n=-0.2210$. g) $n=-0.1795$. h) $n=0.4714$. i) $\alpha=0.0265$.

j) $\alpha=0.0286$. k) $\alpha=0.599$. l) Predictive $\alpha$, Shu [26].

the pure mixing rules, in general, the calculated results overestimated the experimentally measured viscosity, as can be seen by the values of parameters $R_{+}$and $R_{-}$shown in Table 9. In this group, the Double Log $(w)$ (M11) presented the lowest AAD (6.2\%), however, Double Log $(v)$ (M10) and Kendall and Monroe $(m)$ (M6) also provided reasonable results with $8.3 \%$ and $8.9 \% \mathrm{AAD}$, respectively. Chirinos' method (M15) provided undefined results. The M15 equation implies that it can only be used with solvents having kinematic viscosities higher than $0.3 \mathrm{cSt}$, otherwise, the $(v+0.7)$ term is less than 1 and the double logarithm becomes undefined.

For mixing rules with the viscosity blending index (M16-M19), Chevron (w) (M17) provided the best results $(7.7 \% \mathrm{AAD})$, however, always resulting in overprediction, regardless of the temperature or the pressure. It was not possible to obtain results for the Refutas index method (M19) due to double logarithm issues. For a reason similar to that of M15, the M19 equation can only be used with solvents having kinematic viscosities higher than $0.2 \mathrm{cSt}$.

Among the mixing rules with additional parameters (M20-M28), the rules with fitting parameters power law and Lederer (M20-M25) provided quite low deviations. The best result was obtained with Lederer's rule using the volume fractions (M23). This rule presented 2.0\% AAD and $5.8 \%$ MD.

In sort, rules M6, M10, M11, M17, and M20-M25 exhibited the lowest deviations, and M23 presented the best result. It is worth mentioning that M6, M10, M11, and M17 provide essentially predictive results, which makes the performance of these rules more attractive for the live 

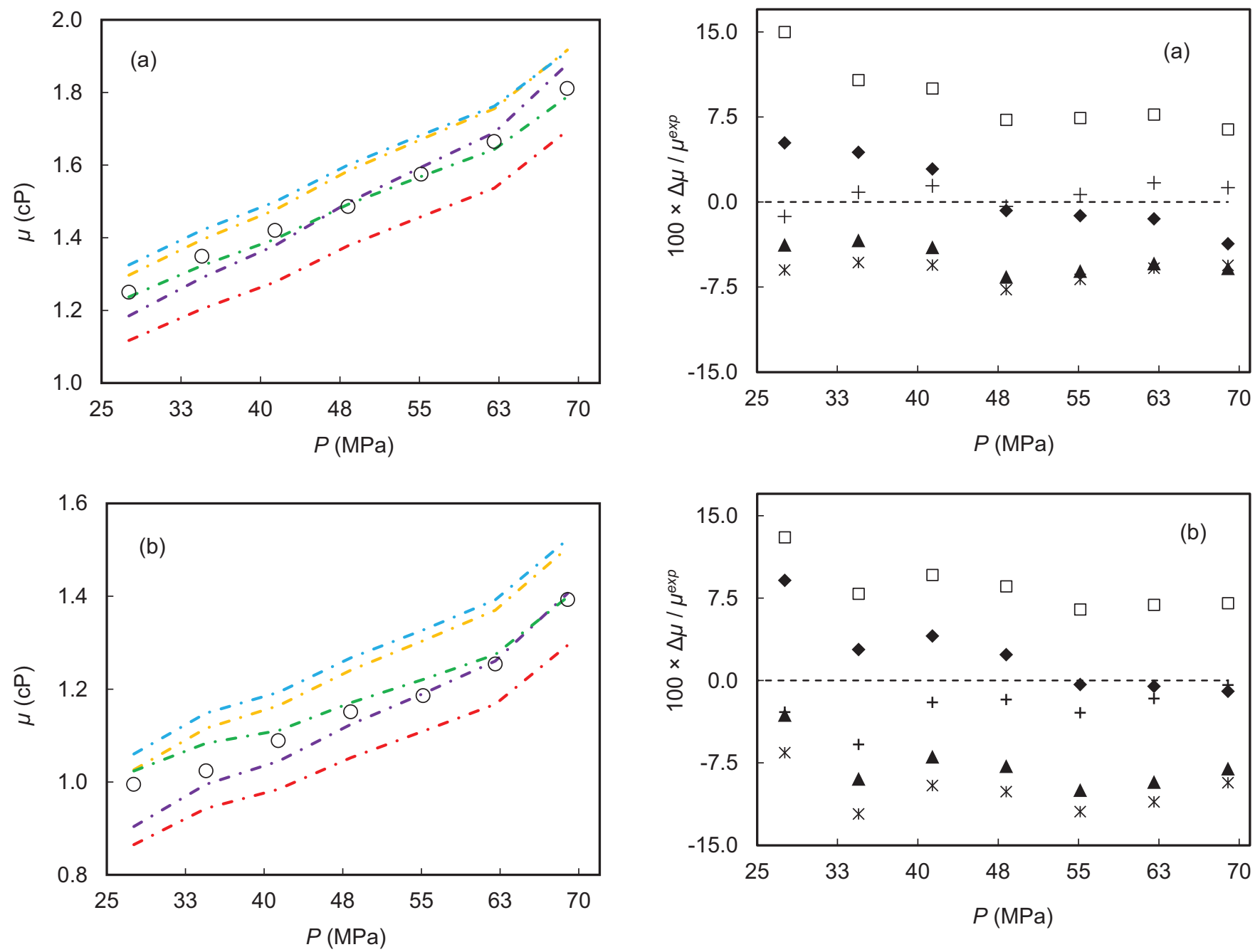

Fig. 7. Experimental dynamic viscosity of the $\mathrm{RLO}+\mathrm{CO}_{2}$ $(87.28: 12.72) \mathrm{w} / \mathrm{w}$ mixture, and the predicted viscosity obtained from five different mixing rules. (O) Experimental, (red) M6, (yellow) M11, (blue) M17, (purple) M22 and (green) M23. (a) $333.15 \mathrm{~K}$ and (b) $353.15 \mathrm{~K}$.

oil $/ \mathrm{CO}_{2}$ system, particularly when experimental viscosities are not available. The results presented in this study related to the performance of the mixing rules agree with those presented by Centeno et al. [32] and Zhang et al. [21], who also reported satisfactory accuracy of the Chevron and Power Law methods (M16-M22) in predicting the viscosity of crude oil blends, and mixtures of bitumen fractions, respectively. On the other hand, the highest deviations (higher than 50\%) were obtained from M9, M13, M14, M27, and M28. The worst performance was obtained with the rule M13, which presented $148.6 \%$ AAD. The M15 and M19 rules are unsuitable for use with $\mathrm{CO}_{2}$ since under the temperature and pressure conditions evaluated in this study, the kinematic viscosity of $\mathrm{CO}_{2}$ ranges from 0.08 to $0.12 \mathrm{cSt}$, which makes the logarithmic terms of these equations undefined.

Fig. 8. Fractional deviations $\Delta \mu=\mu^{\exp }-\mu^{\text {calc }}$ of the experimental densities $\mu^{\exp }$ of the $\mathrm{RLO}+\mathrm{CO}_{2}(87.28: 12.72) \mathrm{w} / \mathrm{w}$ mixture from values $\mu^{\text {calc }}$ estimated from the mixing rules as a

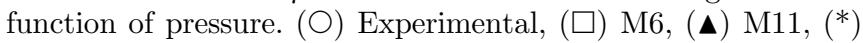
M17, (•) M22, and (+) M23. (a) $333.15 \mathrm{~K}$, (b) $353.15 \mathrm{~K}$.

In Figures $7 \mathrm{a}$ and $7 \mathrm{~b}$, the results obtained with the two best correlative mixing rules (which have adjustable parameters), M22 and M23, as well as with the three best predictive results (M6, M11, and M17), are plotted along with the experimental dynamic viscosity of the $\mathrm{RLO}+\mathrm{CO}_{2}(87.28: 12.72) \mathrm{w} / \mathrm{w}$ mixture. It is possible to note that, among the predictive methods, M11 and M17 tend to overestimate the experimental data, while M6 underestimates them. On the other hand, M22 and M23 tend to present lower deviations with increasing pressure, regardless of the temperature.

In Figures $8 \mathrm{a}$ and $8 \mathrm{~b}$, the relative deviations between the calculated viscosities (shown in Fig. 7) and those obtained experimentally are plotted in a function pressure at (333.15 and 353.15) K, respectively. The temperature change affects only slightly the performance of rules M6 
and M22; however, M11, M17, and M23 presented higher deviations with the increase in temperature.

\section{Conclusion}

This study pointed out that there is a negative volume change upon mixing for the live oil $/ \mathrm{CO}_{2}$ system, which should be considered for accurate prediction of the mixture density. The measured volume change on mixing increases with the increase in temperature and reduces with the increase in pressure. The excess volume approach significantly improves the density correlations. The best performances in calculating the viscosity of the live oil $/ \mathrm{CO}_{2}$ system were achieved by the correlative methods of Lederer and Power law. The predictive methods of Chevron, Double log, and Kendall and Monroe also presented low deviations from the experimental data. This feature presented by these three mixing rules pointed out they are the best options to predict viscosity for fluids with miscible $\mathrm{CO}_{2}$ at the reservoir conditions when experimental mixture data are not available. The Refutas index method, which is one of the most known and used methods, proved to be inefficient for use with $\mathrm{CO}_{2}$ mixtures since it cannot be used for fluids with kinematic viscosity lower than $0.2 \mathrm{cSt}$.

Acknowledgments. This research was carried out in association with the ongoing R\&D project registered as ANP no 20352-1, "Caracterização de Fluidos Complexos em Condições de Reservatórios de Petróleo Brasileiros" (UFRJ/Shell Brasil/ANP), sponsored by Shell Brasil under the ANP R\&D levy as "Compromisso de Investimentos com Pesquisa e Desenvolvimento".

\section{References}

1 Saboorian-Jooybari H. (2015) Analytical estimation of water-oil relative permeabilities through fractures, Oil Gas Sci. Technol. - Rev. IFP Energies Nouvelles 71/3, 31, 1-17.

2 Luo E., Fan Z., Hu Y., Zhao L., Wang J. (2019) An evaluation on mechanisms of miscibility development in acid gas injection for volatile oil reservoirs, Oil Gas Sci. Technol. - Rev. IFP Energies Nouvelles 74, 59, 1-10.

3 De Sant'ana H.B., Ungerer P., Batut C., Moracchini G., Sanchez J., Carrier J., Jensen D.M. (1998) Measurement and prediction of volumetric and transport properties of reservoir fluids at high pressure, Rev. Inst. Fr. Pét. 53/3, 265-281.

4 Liu H., Cheng L., Xiong H., Huang S. (2017) Effects of solvent properties and injection strategies on solventenhanced steam flooding for thin heavy oil reservoirs with semi-analytical approach, Oil Gas Sci. Technol. - Rev. IFP Energies Nouvelles 72/4, 20, 1-14.

5 Zhou M., Bu J., Wang J., Guo X., Huang J., Huang M. (2018) Study on three phase foam for Enhanced Oil Recovery in extra-low permeability reservoirs, Oil Gas Sci. Technol. Rev. IFP Energies Nouvelles 73, 55, 1-8.

6 Hussaina A.A.A., Vincent-Bonnieu S., Bahrim R.Z., Pilus R.M., Rossen W.R. (2020) Impact of crude oil on pregenerated foam in porous media, J. Pet. Sci. Eng. 185, 106628.
7 Manzoor A.A. (2020) Modeling and simulation of polymer flooding with time-varying injection pressure, ACS Omega $\mathbf{5}$, $10,5258-5269$.

8 Mahdaviara M., Helalizadeh A. (2020) A proposed capillary number dependent model for prediction of relative permeability in gas condensate reservoirs: a robust non-linear regression analysis, Oil Gas Sci. Technol. - Rev. IFP Energies Nouvelles 75, 24, 1-21.

9 Ponce R.V., Carvalho M.S., Alvarado V. (2014) Oil recovery modeling of macro-emulsion flooding at low capillary number, J. Pet. Sci. Eng. 119, 112-122.

10 Thomas S. (2007) Enhanced oil recovery - an overview, Oil Gas Sci. Technol. - Rev. IFP Energies Nouvelles 63/1, 9, 9-19.

11 Li H., Zheng S., Yang D. (2013) Enhanced swelling effect and viscosity reduction of solvent(s) $/ \mathrm{CO}_{2} /$ heavy-oil systems, SPE 18, 4, 695-707.

12 Rezk M.G., Foroozesh J. (2018) Determination of mass transfer parameters and swelling factor of $\mathrm{CO}_{2}$-oil systems at high pressures, Int. J. Heat. Mass. Transf. 126, 380-390.

13 Arinelli L.O., Medeiros J.L., Araújo O.Q. (2015) Performance analysis and comparison of membrane permeation versus supersonic separators for $\mathrm{CO}_{2}$ removal from a plausible natural gas of Libra field, Brazil, in: Paper presented at the OTC Brasil, Rio de Janeiro. https://doi.org/10.4043/ 26164-MS

14 Fraga C.T., Pinto A.C., Branco C.C., Pizarro J.O., Paulo C. A. (2015) Brazilian pre-salt: An impressive journey from plans and challenges to concrete results, in: Paper presented at the Offshore Technology Conference, Houston, Texas, USA. https://doi.org/10.4043/25710-MS.

$15 \mathrm{Ju}$ B., Wu Y.S., Qin J. (2015) Computer modeling of the displacement behavior of carbon dioxide in undersaturated oil reservoirs, Oil Gas Sci. Technol. - Rev. IFP Energies Nouvelles 70/6, 951-965.

16 Wang Z., Zhang Y., Liao H. (2020) Experimental investigation on precipitation damage during water alternating flue gas injection, Oil Gas Sci. Technol. - Rev. IFP Energies Nouvelles 75, 45, 1-13.

17 Ferreira F.A., Barbalho T.C., Araújo I.R., Oliveira H.N., Chiavone-Filho O. (2018) Characterization, pressure-volume-temperature properties, and phase behavior of a condensate gas and crude oil, Energy Fuels 32, 4, 5643-5649.

18 He C., Mu L., Xu A., Zhao L., He J., Zhang A., Shan F., Luo E. (2019) Phase behavior and miscible mechanism in the displacement of crude oil with associated sour gas, Oil Gas Sci. Technol. - Rev. IFP Energies Nouvelles 74, 54, 1-9.

19 Dezfuli M.G., Jafari A., Gharibshahi R. (2020) Optimum volume fraction of nanoparticles for enhancing oil recovery by nanosilica/supercritical $\mathrm{CO}_{2}$ flooding in porous medium, J. Pet. Sci. Eng. 185, 106599.

20 Santos D.C., Filipakis S.D., Lima E.R., Paredes M.L. (2019) Solubility parameter of oils by several models and experimental oil compatibility data: implications for asphaltene stability, Pet. Sci. Technol. 37, 13, 1596-1602.

21 Zhang L., Zhang L., Xu Z., Guo X., Xu C., Zhao S. (2019) Viscosity mixing rule and viscosity-temperature relationship estimation for oil sand bitumen vacuum residue and fractions, Energy Fuels 33, 1, 206-214.

22 Arrhenius S.A. (1887) Über die Dissociation der in Wasser gelösten Stoffe, Z. Phys. Chem. 1, 631-648 (in German).

23 Bingham E.C. (1914) The viscosity of binary mixtures, J. Phys. Chem. 18, 2, 157-165. 
24 Kendall J., Monroe K. (1917) The viscosity of liquids II. The viscosity-composition curve for ideal liquid mixtures, $J$. Am. Chem. Soc. 39, 9, 1787-1802.

25 Lederer E.L. (1933) Viscosity of mixtures with and without diluents, in: Presented at 1st World Petroleum Congress, London, UK.

26 Shu W.R. (1984) A viscosity correlation for mixtures of heavy oil, bitumen, and petroleum fractions, SPE 24, 3, 277-282.

27 Cragoe C.S. (1933) Changes in the viscosity of liquids with temperature, pressure and composition, in: Paper presented at the 1st World Petroleum Congress, London, UK.

28 Miadonye A., Latour N., Puttagunta V.R. (2000) A correlation for viscosity and solvent mass fraction of bitumendiluent mixtures, Pet. Sci. Technol. 18, 1-2, 1-14.

29 Nourozieh H., Kariznovi M., Abedi J. (2015) Modeling and measurement of thermo-physical properties for Athabasca bitumen and n-heptane mixtures, Fuel 157, 73-81.

30 Baird C.T. (1989) Guide to petroleum product blending, HPI Consultants, Inc., Austin, Texas.

31 Riazi M.R. (2005) Characterization and properties of petroleum fractions, American Society and Testing Materials, Philadelphia.

32 Centeno G., Reyna G.S., Ancheyta J., Muñoz J.A., Cardona N. (2011) Testing various mixing rules for calculation of viscosity of petroleum blends, Fuel 90, 12, 3561-3570.

33 Nourozieh H., Kariznovi M., Abedi J. (2014) Measurement and prediction of density for the mixture of Athabasca bitumen and pentane at temperatures up to $200{ }^{\circ} \mathrm{C}$, Energy Fuels 28, 5, 2874-2885.

34 Hernández E.A., Reyna G.S., Ancheyta J. (2019) Comparison of mixing rules based on binary interaction parameters for calculating viscosity of crude oil blends, Fuel 249, 198-205.

35 Mehrotra A.K. (1992) A mixing rule approach for predicting the viscosity of $\mathrm{CO}_{2}$-saturated cold lake bitumen and bitumen fractions, J. Pet. Sci. Eng. 6, 4, 289-299.

36 Duncan A.M., Ahosseini A., McHenry R., Depcik C.D., Williams S.M., Scurto A.M. (2010) High-pressure viscosity of biodiesel from soybean, canola, and coconut oils, Energy Fuels 24, 10, 5708-5716.

37 Barabás I., Todorut I.A. (2011) Predicting the temperature dependent viscosity of biodiesel-diesel-bioethanol blends, Energy Fuels 25, 12, 5767-5774.

38 Muhammad A., Azeredo R.B.V. (2014) 1H NMR spectroscopy and low-field relaxometry for predicting viscosity and API gravity of Brazilian crude oils - A comparative study, Fuel 130, 126-134.

39 Dehaghani A.H.S., Badizad M.H. (2016) Experimental study of Iranian heavy crude oil viscosity reduction by diluting with heptane, methanol, toluene, gas condensate and naphtha, Petroleum 2, 4, 415-424.

40 Pallares F.R., Taylor S.D., Satyro M.A., Marriott R.A., Yarranton H.W. (2016) Prediction of viscosity for characterized oils and their fractions using the expanded fluid model, Energy Fuels 30, 9, 7134-7157.

41 Liu Z., Wu G., Wei C. (2020) Physical experiments and numerical simulations of viscosity reducer flooding for ordinary heavy oil, J. Pet. Sci. Eng. 192, 107194.

42 Sánchez N.M., Klerk A. (2020) Viscosity mixing rules for bitumen at 1-10 wt\% solvent dilution when only viscosity and density are known, Energy Fuels 34, 7, 8227-8238.

43 Ratcliff G.A., Khan M.A. (1971) Prediction of the viscosities of liquid mixtures by a group solution model, Can. J. Chem. Eng. 49, 125-129.
44 Lian L., Qin J., Yang S., Yang Y., Li S., Chen X. (2014) An improved viscosity model for $\mathrm{CO}_{2}$-crude system, Petrol. Explor. Develop. 41, 5, 648-653.

45 Peng R.Y., Robinson D.B. (1976) A new two constant equation of state, Ind. Eng. Chem. Fundam. 15, 1, 59-64.

46 Nazeri M., Chapoy A., Burgass R., Tohidi B. (2018) Viscosity of $\mathrm{CO}_{2}$-rich mixtures from $243 \mathrm{~K}$ to $423 \mathrm{~K}$ at pressures up to $155 \mathrm{MPa}$ : new experimental viscosity data and modelling 118, 100-114.

47 Seyyedi M., Mahzari P., Sohrabi M. (2018) A comparative study of oil compositional variations during $\mathrm{CO}_{2}$ and carbonated water injection scenarios for EOR, J. Pet. Sci. Eng. 164, 685-695.

48 Nasrabadi H., Firoozabadi A., Tausif K.A. (2009) Complex flow and composition path in $\mathrm{CO}_{2}$ injection schemes from density effects in 2 and 3D, in: Paper presented at the SPE Annual Technical Conference and Exhibition, New Orleans, Louisiana. https://doi.org/10.2118/124803-MS.

49 Elias A., Trevisan O.V. (2016) An experimental investigation on phase behavior of a light oil and $\mathrm{CO}_{2}$, J. Pet. Sci. Eng. 145, 22-33.

50 Ashcroft S., Ben Isa M. (1997) Effect of dissolved gases on the densities of hydrocarbons, J. Chem. Eng. Data 42, 6, 1244-1248.

51 Nasir F.M., Nurul A.A. (2008) Miscible $\mathrm{CO}_{2}$ injection: Sensitivity to fluid properties, in: Paper presented at the SPE Asia Pacific Oil and Gas Conference and Exhibition, Perth, Australia. https://doi.org/10.2118/115314-MS.

52 Lansangan R.M., Smith J.L. (1993) Viscosity, density, and composition measurements of $\mathrm{CO}_{2}$ /West Texas oil systems, SPE Res. Eng. 8, 175-182.

53 Valero A.M.C., Feitosa F.X., Sant'Ana H.B. (2020) Density and volumetric behavior of binary $\mathrm{CO} 2+$ n-decane and ternary $\mathrm{CO} 2+$ n-decane + naphthalene systems at high pressure and high temperature, J. Chem. Eng. Data 65, 7, 3499-3509.

54 Santos D.C., Gonçalves I.S., Mehl A., Couto P., Paredes M. L.L. (2021) Density of n-Heptane + n-Dodecane and Carbon Dioxide + n-Heptane + n-Dodecane Mixtures up to $70 \mathrm{MPa}$ from (293.15 to 363.15) K, J. Chem. Eng. Data 66, 3, 1305-1318.

55 Katz D.L., Firoozabadi A. (1978) Predicting Phase behavior of condensate/crude-oil systems using methane interaction coefficients, SPE 30, 11, 1649-1655.

56 Lagourette B., Boned C., Guirons H., Xans P., Zhou H. (1992) Densimeter calibration method versus temperature and pressure, Meas. Sci. Technol. 3, 8, 699-703.

57 Comuñas M.J., Bazile J.P., Baylaucq A., Boned C. (2008) Density of diethyl adipate using a new vibrating tube densimeter from (293.15 to 403.15) K and up to $140 \mathrm{MPa}$. Calibration and measurements, J. Chem. Eng. Data 53, 4, 986-994.

58 Wagner W., Pruss A. (2002) The IAPWS Formulation 1995 for the thermodynamic properties of ordinary water substance for general and scientific use, J. Phys. Chem. Ref. Data 31, 2, 387-535.

59 Span R., Wagner W. (1996) A new equation of state for carbon dioxide covering the fluid region from the triple-point temperature to $1100 \mathrm{~K}$ at Pressures up to $800 \mathrm{MPa}$, J. Phys. Chem. Ref. Data 25, 6, 1509-1596.

60 Peng Z., Li X., Sun Z. (2020) A relative permeability model for CBM reservoir, Oil Gas Sci. Technol. - Rev. IFP Energies Nouvelles 75, 2, 1-9. 
61 Lobe V.M. (1973) A model for the viscosity of liquid-liquid mixtures, M.Sc Thesis, University of Rochester, New York.

62 Bermúdez M.M., Molina L.A., Tiburcio W.E., Luna L.A., Solis O.E. (2013) $(p, \rho, T)$ Behavior for the binary mixtures carbon dioxide + heptane and carbon dioxide + tridecane, J. Chem. Eng. Data 58, 5, 1255-1264.

63 Zhang Y., Liu Z., Liu W., Zhao J., Yang M., Liu Y., Wang D., Song Y. (2014) Measurement and modeling of the densities for $\mathrm{CO}_{2}+$ dodecane system from $313.55 \mathrm{~K}$ to 353.55 $\mathrm{K}$ and pressures up to $18 \mathrm{MPa}$, J. Chem. Eng. Data 59, 11, 3668-3676.

64 Bazile J.P., Nasri D., Hamani A.W., Galliero G., Daridon J.L. (2018) Excess volume, isothermal compressibility, isentropic compressibility and speed of sound of carbon dioxide + n-heptane binary mixture under pressure up to $70 \mathrm{MPa}$. I Experimental Measurements, J. Supercrit. Fluid. 140, 218-232.

65 Bazile J.P., Nasri D., Hamani A.W., Galliero G., Daridon J. L. (2019) Density, speed of sound, compressibility, and excess properties of carbon dioxide + n-dodecane binary mixtures from 10 to $70 \mathrm{MPa}$, J. Chem. Eng. Data 64, 7, 3187-3204.

66 Tohidi B., Burgass R.W., Danesh A., Todd A.C. (2001) Viscosity and density of methane + methylcyclohexane from (323 to 423 ) K and pressures to $140 \mathrm{MPa}$, J. Chem. Eng. Data 46, 2, 385-390.

67 Regueira T., Pantelide G., Yan W., Stenby E.H. (2016) Density and phase equilibrium of the binary system methane + n-decane under high temperatures and pressures, Fluid Phase Equilib. 428, 48-61.

68 Luo E., Fan Z., Hu Y., Zhao L., Wang J. (2019) An evaluation on mechanisms of miscibility development in acid gas injection for volatile oil reservoirs, Oil Gas Sci. Technol. - Rev. IFP Energies nouvelles 74, 59, 1-10.

69 Kian K., Scurto A.M. (2018) Viscosity of compressed $\mathrm{CO}_{2^{-}}$ saturated n-alkanes: $\mathrm{CO}_{2} /$ n-hexane, $\mathrm{CO}_{2} / \mathrm{n}$-decane, and $\mathrm{CO}_{2} /$ n-tetradecane, J. Supercrit. Fluid 133, 1, 411-420.

70 Fenghour A., Wakeham W.A., Vesovic V. (1998) The viscosity of carbon dioxide, J. Phys. Chem. Ref. Data 27, $31,31-44$. 